\title{
Maternal and fetal amino acid metabolism in gestating sows
}

\author{
Guoyao Wu, ${ }^{1,2,3^{*}}$ Fuller W. Bazer, ${ }^{1,2}$ Gregory A. Johnson,, ${ }^{2}$ Robert. C. \\ Burghardt, ${ }^{2}$ Xilong Li, ${ }^{1}$ Zhaolai Dai, ${ }^{3}$ Junjun Wang ${ }^{3}$, and Zhenlong $\mathrm{Wu}^{3}$ \\ ${ }^{1}$ Department of Animal Science and ${ }^{2}$ Department of Veterinary Integrative Biosciences, Texas A\&M \\ University, College Station, Texas, USA 77843-2471; ${ }^{3}$ State Key Laboratory of Animal Nutrition, \\ China Agricultural University, Beijing, China 100193
}

Among livestock species, swine exhibit the most severe naturally-occurring intra-uterine growth restriction (IUGR) primarily due to a reduction in net protein synthesis. Thus, new knowledge about fetal metabolism of amino acids (AA), which are building blocks for proteins and regulators of intracellular protein turnover, can provide a solution to this problem. Among all $\mathrm{AA}$, requirements of glutamate and glutamine by fetal pigs are quantitatively the highest, but cannot be met through uterine uptake alone. Nearly all glutamate and $\sim 70 \%$ glutamine in diets for gestating swine are degraded in the maternal small intestine and, therefore, do not enter the portal circulation. This necessitates interorgan AA metabolism involving maternal skeletal muscle, placenta, and fetal skeletal muscle to synthesize glutamate and glutamine from branched-chain AA, as well as storage of glutamate and glutamine in allantoic and amniotic fluids. The porcine placenta does not degrade arginine or glutamine, leading to their maximal transfer from maternal to fetal blood. Therefore, maternal sources of ornithine and proline play a major role in the placental synthesis of polyamines needed for placental growth including placental vascular growth. Likewise, during late gestation, uterine uptake of arginine, proline and aspartate/asparagine cannot meet requirements for optimal fetal growth. To provide sufficient arginine, the fetal small intestine synthesizes citrulline and arginine from glutamate and glutamine, and fetal kidneys convert citrulline into arginine. Collectively, glutamine and arginine are major sources of AA nitrogen transferred between mother and fetus. Results of recent studies indicate that dietary supplementation with these two AA can ameliorate IUGR in swine. These findings greatly advance the field of maternal-fetal AA metabolism in pigs, but also have important implications for improving reproductive efficiency in swine production worldwide.

\section{Introduction}

Domestic pigs have no brown adipose tissue (Satterfield \& Wu 2011), but possess a high capacity for synthesizing triacylglycerides in white adipose tissue after birth (Smith et al. 1999). Excess white fat in the body causes insulin resistance, metabolic disorders, and impaired lactation performance in animals, including swine (Jobgen et al. 2006; Wu 2010a). Thus, during gestation, gilts or multiparous sows are usually fed a substantially reduced amount of

E-mail: g-wu@tamu.edu 
diet (e.g., 2 to $2.2 \mathrm{~kg} /$ day that is approximately $50 \%$ of their ad libitum feed consumption) to reduce energy intake and prevent females from becoming overweight (Ashworth 1991; Kim et al. 2009; Pond et al. 1969, 1981). This strategy, however, results in inadequate provision of dietary amino acids (AA) to both mother and fetus (Wu et al. 2010). Amino acids are the building blocks for proteins in cells and, importantly, they are also precursors for synthesis of glucose and nitrogenous substances [e.g., nitric oxide (NO), polyamines, creatine, dopamine, thyroid hormones, and catecholamines] essential for whole body homeostasis (Wu 2009). Thus, AA have nutritional, physiological, and regulatory roles in animals (Fig. 1).

Current feeding programs for gestating swine remain suboptimal due, in part, to inadequate knowledge about maternal and fetal AA nutrition (Kim et al. 2009). Thus, among livestock species, swine suffer the greatest prenatal loss (up to 50\%) and exhibit the most severe naturallyoccurring intra-uterine growth restriction (IUGR) primarily because of a reduction in net protein synthesis (Vallet et al. 2002; Wu et al. 2006). This provides an impetus to develop novel and effective strategies to improve pregnancy outcome in pigs. The major objectives of this article are to highlight maternal-fetal AA metabolism and nutrition in gestating swine. Readers are referred to the work of Bazer et al. (2013) for recent advances in the roles of AA in regulating embryonic growth, survival and development during early pregnancy.

\section{Sources of AA for the fetus}

The porcine fetus receives AA from its mother via placental transport and can synthesize some AA, including alanine, arginine, asparagine, aspartate, cysteine, glutamate, glutamine, glycine, proline, serine, and tyrosine (Wu et al. 2010). Fetal blood, which contains relatively high concentrations of glutamine and glycine, is the parenteral source of all AA for the fetus. In addition, allantoic fluid, which is derived from both maternal and fetal sources, is a reservoir of AA for the fetus and contains unusually high concentrations of arginine (e.g., 4 to $6 \mathrm{mM}$ )

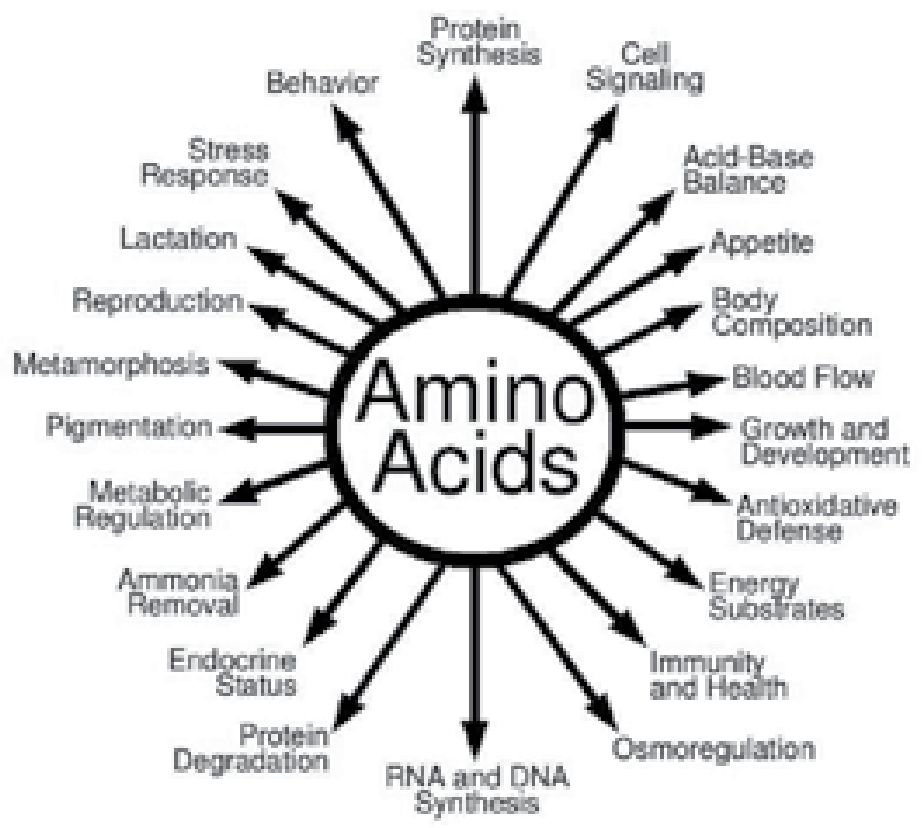

Fig. 1 Nutritional, physiological and regulatory roles of AA in animals. Reprinted from Wu (2010) with permission from American Society of Nutrition. 
and glycine ( 4 to $5 \mathrm{mM}$ ) during early and late gestation, respectively (Table 1 ). Nutrients in the allantoic fluid are transported through the allantoic epithelium, enter the fetal-placental circulation, and are utilized by fetal-placental tissues (Figure 2). During early pregnancy, marked increases in concentrations of each AA in allantoic fluid are not accounted for by changes in allantoic fluid volume (Table 1) or by changes in concentrations of AA in maternal and fetal plasma (Wu et al. 1995). AA may play an important role in regulating osmolality in allantoic fluid.

Amniotic fluid is derived from both the fetus (kidneys, lungs, epidermis, and fetal blood vessels in the placenta and umbilical cord) and the mother (blood vessels via amniotic membranes) (Schmidt 1992). This fluid is removed by both the fetus and the mother through the same

Table 1. Amino acid composition in the body and allantoic fluid of fetal pigs

\begin{tabular}{|c|c|c|c|c|c|c|c|c|c|c|}
\hline \multirow[t]{2}{*}{ Amino acid } & \multicolumn{5}{|c|}{$\begin{array}{l}\text { AA composition in fetal pigs on different } \\
\text { days of gestation (mg AA/g wet weight })^{1}\end{array}$} & \multicolumn{5}{|c|}{$\begin{array}{l}\text { AA composition in allantoic fluid of fetal } \\
\text { pigs on different days of gestation }(\mu \mathrm{M})^{2}\end{array}$} \\
\hline & 40 & 60 & 90 & 110 & 114 & 30 & 40 & 60 & 90 & 110 \\
\hline Alanine $^{4}$ & 3.63 & 3.01 & 4.26 & 5.87 & 6.46 & 233 & 281 & 92 & 396 & 669 \\
\hline Arginine $^{5}$ & 3.77 & 3.24 & 4.58 & 5.85 & 6.47 & 185 & 4103 & 642 & 128 & 465 \\
\hline Aspartate $^{4}$ & 2.90 & 2.34 & 3.01 & 3.92 & 4.25 & 16 & 164 & 85 & 170 & 195 \\
\hline Asparagine $^{4}$ & 2.41 & 1.94 & 2.50 & 3.25 & 3.53 & 61 & 280 & 56 & 83 & 139 \\
\hline Citrulline $^{4}$ & 0.023 & 0.024 & 0.032 & 0.046 & 0.054 & 10 & 72 & 46 & 96 & 30 \\
\hline Cysteine ${ }^{4}$ & 0.78 & 0.67 & 0.92 & 1.19 & 1.28 & 70 & 220 & 308 & 230 & 604 \\
\hline Glutamate $^{4}$ & 4.94 & 4.21 & 5.34 & 6.81 & 7.72 & 112 & 2383 & 609 & 1182 & 1056 \\
\hline Glutamine $^{5}$ & 3.19 & 2.72 & 3.44 & 4.39 & 4.98 & 638 & 3442 & 273 & 652 & 701 \\
\hline Glycine $^{5}$ & 3.69 & 3.60 & 6.53 & 9.23 & 10.8 & 803 & 360 & 195 & 4227 & 3054 \\
\hline Histidine $^{3}$ & 1.54 & 1.05 & 1.42 & 1.85 & 2.07 & 76 & 687 & 61 & 73 & 78 \\
\hline Hydroxyproline ${ }^{4}$ & 0.50 & 0.91 & 2.08 & 3.01 & 3.48 & 61 & 49 & 28 & 41 & 82 \\
\hline Isoleucine ${ }^{3}$ & 2.18 & 1.71 & 2.08 & 2.61 & 2.89 & 28 & 80 & 31 & 10 & 13 \\
\hline Leucine $^{3}$ & 5.04 & 3.83 & 4.82 & 6.13 & 6.75 & 63 & 153 & 38 & 14 & 33 \\
\hline Lysine $^{3}$ & 5.15 & 3.42 & 4.14 & 5.19 & 5.77 & 362 & 1950 & 390 & 214 & 617 \\
\hline Methionine $^{3}$ & 1.39 & 1.05 & 1.34 & 1.71 & 1.86 & 17 & 31 & 16 & 15 & 273 \\
\hline Ornithine $^{4}$ & 0.08 & 0.075 & 0.09 & 0.12 & 0.13 & 124 & 2524 & 645 & 76 & 85 \\
\hline Phenylalanine $^{3}$ & 2.78 & 2.03 & 2.52 & 3.14 & 3.44 & 36 & 40 & 34 & 195 & 51 \\
\hline Proline $^{5}$ & 3.68 & 4.07 & 5.42 & 7.06 & 7.82 & 261 & 144 & 46 & 117 & 336 \\
\hline Serine $^{4}$ & 3.05 & 2.35 & 2.96 & 3.98 & 4.33 & 553 & 902 & 79 & 603 & 1218 \\
\hline Taurine $^{4}$ & 0.28 & 0.23 & 0.28 & 0.36 & 0.38 & 457 & 641 & 298 & 450 & 658 \\
\hline Threonine $^{3}$ & 2.52 & 1.90 & 2.42 & 2.95 & 3.24 & 218 & 1780 & 89 & 343 & 545 \\
\hline Tryptophan ${ }^{3}$ & 0.72 & 0.61 & 0.82 & 1.03 & 1.11 & 13 & 53 & 69 & 164 & 574 \\
\hline Tyrosine $^{4}$ & 2.13 & 1.58 & 1.85 & 2.27 & 2.43 & 45 & 70 & 22 & 42 & 39 \\
\hline Valine $^{3}$ & 3.40 & 2.41 & 3.13 & 3.88 & 4.21 & 80 & 163 & 66 & 57 & 144 \\
\hline
\end{tabular}

${ }^{1}$ Adapted from Wu et al. (1999).

${ }^{2}$ Adapted from Wu et (1995) and Wu et al (1996).

${ }^{3}$ Traditionally classified as "nutritionally essential AA" (EAA).

${ }^{4}$ Traditionally classified as "nutritionally nonessential AA" (NEAA).

${ }^{5}$ Currently classified as "conditionally essential AA" (CEAA; Wu 2013). 


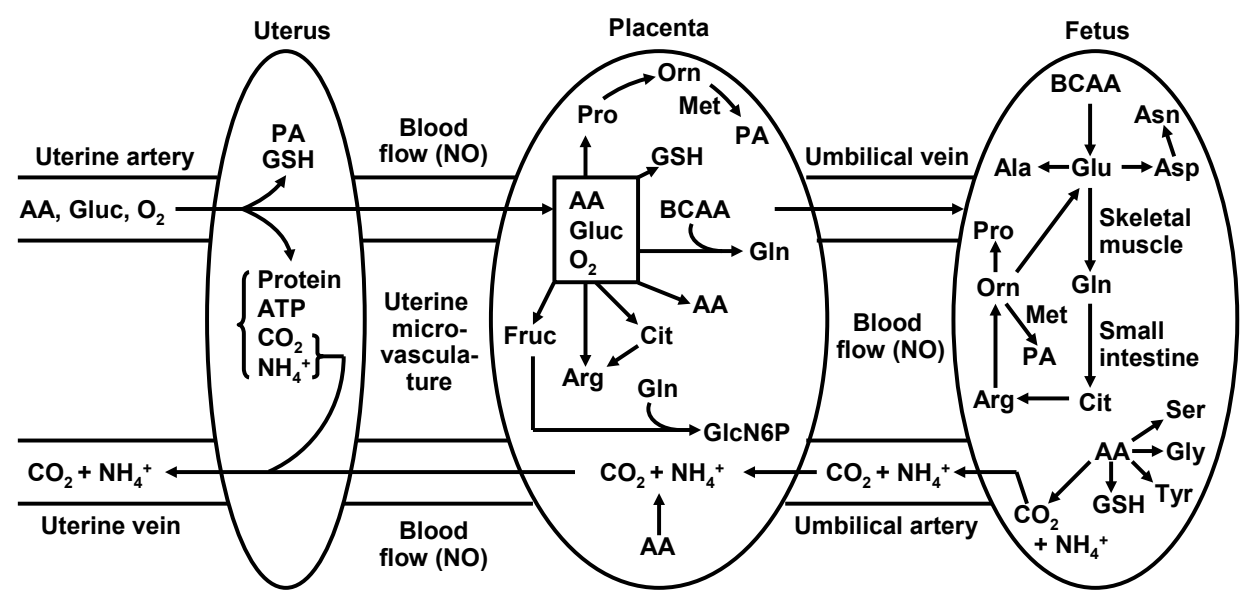

Fig. 2 Provision of AA from mother to fetus in gestating swine. Uterine artery delivers AA, glucose, and oxygen from maternal arterial blood to the uterus and, through the uterine microvasculature, to the placenta. Umbilical vein supplies AA, glucose, and oxygen from the placenta to the fetus. Adapted from Wu (2013).

channels, along with the participation of the fetal intestine following swallowing. Thus, with the development of intestinal amino acid transport systems during gestation, the drinking of amniotic fluid provides the enteral source of AA for fetal utilization. The nutritional significance of amniotic fluid is graphically illustrated by the finding that esophageal ligation, which prevents the entry of this fluid into the small intestine, results in IUGR in the fetus (Trahair \& Harding 1995). The amniotic fluid provides a large amount of glutamine for supporting growth and development of the fetal small intestine (Dekaney et al. 2003). Likewise, in gestating gilts fed a low-protein ( $0.5 \%$ crude protein) diet, reduced concentrations of glutamine in amniotic fluid are associated with IUGR between d 0 and 60 of gestation (Wu et al. 1998a,b).

Based on growth or nitrogen balance, AA were traditionally classified as nutritionally essential or nonessential (Wu 2010b). Nutritionally essential AA (EAA) were defined as those AA whose carbon skeletons are not synthesized by animals, whereas nutritionally nonessential AA (NEAA) as those AA which are synthesized de novo in adequate amounts by animals to meet requirements for maintenance, growth, development and health and, therefore, need not be provided in the diet. However, EAA and NEAA are only categorizations according to definitions, and physiological functions of AA should be taken into consideration in formulating diets for animals. In fetal pigs, concentrations of free NEAA, the content of NEAA in proteins, and, therefore, requirements of NEAA for tissue protein synthesis are greater than those of EAA at all gestational stages (Table 3). To date, there is no compelling experimental evidence for sufficient synthesis of NEAA by swine or other animals to meet requirements for maximum growth or optimal health (Wu et al. 2013). Thus, in recent years, some NEAA have been reclassified as conditionally essential AA (CEAA), which are defined as those AA that normally can be synthesized in adequate amounts by animals, but which must be provided in the diet to meet optimal needs under certain conditions (e.g., gestation, lactation, and weaning) wherein rates of utilization are greater than rates of synthesis (Wu 2009).

\section{Limitations to uterine capacity in pigs}

Fetal growth and survival in mammals is affected by complex factors, including uterine capacity and environment, including AA nutrition (Ashworth et al. 2001; Wu et al. 2006). In 
pigs, inadequate uterine capacity is a major factor contributing to suboptimal fetal growth and survival after d 25 of gestation (Bazer et al., 2009). This problem is even more severe in modern highly prolific breeds than in breeds used in the swine industry $30 \mathrm{yr}$ ago due to selection for increased litter size (Vallet et al. 2009). For example, IUGR piglets ( $<1.10 \mathrm{~kg}$ birth weights) can account for up to $25 \%$ of total piglets born and represent $76 \%$ of preweaning deaths in pigs (Wu et al. 2010). At present, there is no nutritional support to increase growth and survival of IUGR piglets during postnatal periods to compensate for their reduced birth weight and, therefore, they are often culled on farms (Vallet \& Freking 2006).

The gestating pig develops a noninvasive, diffuse type of epitheliochorial placentae, whose weights, lengths, and surface area vary greatly among conceptuses within the same uterus (Bazer et al. 2008). Immediately after implantation of the conceptus, various genes are expressed in the trophectoderm to initiate placental formation (Bazer et al. 2009; Vonnahme \& Ford 2004). Implantation begins around d 14 of gestation and is completed around d 18 in pigs, followed by placentation (Geisert \& Yelich 1997). The placenta undergoes rapid formation of new blood vessels (i.e., angiogenesis) and marked growth during pregnancy (Reynolds \& Redmer 2001). Thus, blood vessels are clearly visible in porcine placentae and allantoic membranes on d 25 of pregnancy (Li et al. 2010). Notably, the porcine placenta grows rapidly between $\mathrm{d} 20$ and 60 of gestation and its development is nearly maximal by d 70 (Knight et al. 1977; Wu et al. 2005), a period preceding rapid fetal growth (Table 2). Placental angiogenesis is necessary to increase blood flow from the placenta to the fetus that supplies nutrients from mother to fetus (Bazer et al. 1988; Ford et al. 2002; Reynolds et al. 2006). The functional capacity of the uterus and the placenta for provision of nutrients and oxygen from mother to fetus is vital to fetal survival, growth and development (Wu et al. 2004; Bazer et al. 2008).

\section{Uterine uptake of AA for fetal growth in gestating pigs}

To assess the availability of AA present in maternal blood to the placenta, we previously determined uterine uptake of AA in gestating gilts on d 110-114 of pregnancy based on uterine arteriovenous concentrations and the rate of uterine blood flow $(243 \mathrm{~mL} / \mathrm{min} /$ fetus $)$. All AA, except for $\gamma$-aminobutyric acid, which is negligible $(<0.1 \mu \mathrm{M})$ in uterine arterial and venous plasma, are taken up by the uterus of pregnant gilts (Table 3). Uterine uptake of glutamine is greatest, followed by glycine, proline, leucine, alanine, lysine, and arginine, in decreasing order. However, uterine uptake of aspartate/asparagine and glutamate represents only 9 and $29 \%$ of fetal accretion, respectively. Note that glycine, which has versatile physiological functions (Wang et al. 2013), has the highest rate of accretion in fetal tissue proteins among all AA (Table 3). Because AA are oxidized by the fetus, most of the NEAA and CEAA (including glutamine, glutamate, aspartate, glycine, arginine, and proline) taken up by the uterus are likely to be insufficient for fetal protein synthesis. Because hydroxyproline is not utilized for protein

Table 2. Placental and fetal weights as well as allantoic and amniotic fluid volumes in gestating pigs

\begin{tabular}{lcccccccc}
\hline \multirow{2}{*}{ Variable } & \multicolumn{9}{c}{ Days of gestation } \\
& 18 & 20 & 30 & 40 & 60 & 90 & 110 & 114 \\
\hline Placental weight, g & -- & 0.22 & 33 & 59 & 182 & 208 & 237 & 225 \\
Fetal weight, g & 0.030 & 0.063 & 1.7 & 11 & 130 & 596 & 1176 & 1486 \\
Allantoic fluid, ml & 1.0 & 4.1 & 227 & 74 & 347 & 83 & 56 & 29 \\
Amniotic fluid, ml & 0.02 & 0.06 & 2.2 & 12.5 & 119 & 127 & 81 & 32 \\
\hline
\end{tabular}

Adapted from Bazer 1988 and Wu et al. (2005). 
Table 3. Dietary intake of AA, entry of AA into the portal vein, uterine uptake of AA and fetal accretion of AA in gilts at Days 110-114 of gestation

\begin{tabular}{|c|c|c|c|c|c|}
\hline$A A$ & $\begin{array}{c}\text { AA content in } \\
\text { maternal diet } \\
(\%, \text { as-fed basis) })^{1}\end{array}$ & $\begin{array}{c}\text { AA intake from } 2 \\
\text { kg diet by gilt (g/ } \\
\text { day/giltt) }\end{array}$ & $\begin{array}{c}\text { Entry of dietary } \\
A A \text { into portal } \\
\text { vein (g/day/giltt) }\end{array}$ & $\begin{array}{l}\text { Uterine uptake } \\
\text { of } A A(\mathrm{mg} / \text { day/ } \\
\text { fetus })^{3}\end{array}$ & $\begin{array}{c}\text { AA accretion in } \\
\text { fetal pig }(\mathrm{mg} / \text { day/ } \\
\text { fetus })^{3}\end{array}$ \\
\hline Alanine & 0.78 & 15.6 & 11.7 & 891 & 723 \\
\hline Arginine & 0.70 & 14.0 & 7.22 & 749 & 732 \\
\hline Aspartate & 0.76 & 15.2 & 0.65 & 76 & 461 \\
\hline Asparagine & 0.58 & 11.6 & 8.68 & 264 & 382 \\
\hline Citrulline & 0.00 & 0.00 & 0.00 & 388 & 7.0 \\
\hline Cysteine $^{3}$ & 0.23 & 4.6 & 3.28 & 202 & 136 \\
\hline Glutamate & 1.07 & 21.4 & 0.74 & 420 & 922 \\
\hline Glutamine & 1.22 & 24.4 & 6.92 & 2571 & 595 \\
\hline Glycine & 0.55 & 11.0 & 7.76 & 1617 & 1375 \\
\hline Histidine & 0.33 & 6.6 & 4.54 & 281 & 240 \\
\hline Hydroxyproline & 0.00 & 0.00 & 0.00 & 119 & 434 \\
\hline Isoleucine & 0.51 & 10.2 & 5.70 & 416 & 328 \\
\hline Leucine & 1.17 & 23.4 & 13.3 & 1031 & 756 \\
\hline Lysine & 0.58 & 11.6 & 7.48 & 762 & 661 \\
\hline Methionine & 0.18 & 3.6 & 2.45 & 245 & 202 \\
\hline Ornithine & 0.00 & 0.00 & 0.00 & 218 & 14.5 \\
\hline Phenylalanine & 0.62 & 12.4 & 8.32 & 452 & 381 \\
\hline Proline & 1.03 & 20.6 & 10.8 & 1179 & 887 \\
\hline Serine & 0.50 & 10.0 & 7.14 & 575 & 471 \\
\hline Taurine & 0.00 & 0.00 & 0.00 & 122 & 38.3 \\
\hline Threonine & 0.49 & 9.8 & 6.07 & 482 & 361 \\
\hline Tryptophan & 0.13 & 2.6 & 1.81 & 204 & 137 \\
\hline Tyrosine & 0.45 & 9.0 & 6.19 & 340 & 254 \\
\hline Valine & 0.65 & 13.0 & 7.27 & 585 & 455 \\
\hline
\end{tabular}

The diet was based on corn and soybean meal. Feed intake by each gilt was $2.0 \mathrm{~kg}$ per day during the entire period of gestation (Wu et al. 2010). The average litter size at d 110-114 of gestation was 10.0 fetuses per gilt. ${ }^{2}$ Assuming true ileal digestibility of $86 \%$ for each AA.

${ }^{3}$ Days 110-114 of gestation (Wu et al. 1999).

Values for the bioavailability (\%) AA in the lumen of the small intestine to the portal vein are based on those for growing pigs (Wu et al. 2010): Ala, 87; Arg, 60; Asn, 87; Asp, 5; Cys, 83; Glu, 4; Gln, 33; Gly, 82; His, 80 lle, 65; Leu, 66; Lys, 75; Met, 79; Phe, 78; Pro, 61; Ser, 83; Thr, 72; Trp, 81; Tyr, 80; and Val, 65). Products of intestinal AA metabolism that enter the portal vein are not included.

synthesis, peptide-bound hydroxyproline in fetal pigs is derived from proline. Pathways for AA synthesis via inter-organ cooperation in mammals including pigs are now largely known (Wu 2013) and are illustrated in Figure 3. For example, the maternal and fetal skeletal muscle, as well as the placenta of gestating swine synthesize glutamine and glutamate from branched-chain AA and $\alpha$-ketoglutarate. In both the sow and her fetuses, the small intestine converts arterial glutamine as well as glutamine, glutamate, and proline within its lumen into citrulline and arginine. The citrulline and ornithine transported from the maternal blood is used by almost 
all cell types in the fetus for the synthesis of arginine and proline, respectively. At present, quantitative aspects of placental uptake of AA in gestating swine are unknown due to the lack of data on placental blood flow. However, the parity between uterine uptake and accretion of AA in fetal pigs is particularly large for glutamate and aspartate, and to a lesser extent, for proline and arginine. Therefore, these AA must be synthesized from branched-chain AA and glucose, and possibly from other AA by the placenta and/or the fetus.

Fetal to maternal ratios of glutamine and branched-chain AA in plasma are much greater and less than 1, respectively (Wu et al. 1995). For example, in the plasma of pigs, fetal/maternal ratios for glutamine are 3.87 and 2.88, respectively, at $d 45$ and 110 of gestation. Such disparate glutamine levels between mother and fetus suggest that glutamine is actively synthesized by the placenta, which then releases glutamine into the fetal circulation. In contrast, fetal/maternal ratios for branched-chain AA are less than 0.70 between $\mathrm{d} 45$ and 110 of gestation, suggesting extensive catabolism of uterus-derived BCAA in the placenta. Results of both enzymological and metabolic studies indicate that branched-chain amino acids and glucose donate the amino group and the carbon skeleton, respectively, for the synthesis of glutamine by the porcine placenta (Self et al. 2004). Interestingly, there is no detectable catabolism of glutamine in the porcine placenta throughout pregnancy (Self et al. 2004), which ensures maximum output of glutamine by this tissue (Figure 3). These findings provide valuable insight into the dynamic role of the placenta in fetal metabolism and nutrition.

\section{Utilization of AA for placental growth and development}

The placenta uses both EAA and NEAA to synthesize proteins to support its growth and development. Protein synthesis is stimulated by polyamines (i.e., putrescine, spermidine, and spermine) (Wu et al. 2008). Unlike most other tissues which convert arginine to polyamines via arginase and ornithine decarboxylase, the porcine placenta lacks arginase and, therefore, cannot synthesize ornithine from arginine (Wu et al. 2005). This feature of AA catabolism helps maximize the transfer of arginine from maternal to fetal blood, leading to an unusual abundance of arginine in porcine allantoic fluid for supporting fetal growth (Wu et al. 1996). At present, it is unknown whether arginine can be metabolized in the placenta to generate putrescine via arginine decarboxylase and agmatinase (Bazer et al. 2013). Interestingly, the porcine placenta expresses a high activity of proline oxidase for oxidizing maternal blood-derived proline to form pyrroline-5-carboxylate, a precursor of ornithine and, therefore, polyamines (Figure 3). The synthesis of polyamines requires methionine as a donor of the methyl group via the formation of S-adenosylmethionine. In maternal tissues, proline is synthesized from arginine (Wu et al. 2011). Besides polyamines, NO (a product of arginine degradation by NO synthase) plays an important role in placental growth, including placental angiogenesis and vascular growth, as well as blood flow (Meininger \& Wu 2002; Wu et al. 2009). Generation of NO from arginine is increased by some AA (e.g., taurine and citrulline) and is inhibited by others (e.g., lysine and homocysteine) (Wu \& Meininger 2002). Thus, appropriate proportions and amounts of all AA, including EAA and NEAA, are important factors affecting NO synthesis and uterine capacity.

Besides serving as substrates for placental synthesis of protein and nitrogenous metabolites, AA (e.g., arginine, glutamine, and leucine) regulate these metabolic pathways via various cell signaling mechanisms, including phosphorylation of the mechanistic target of rapamycin (MTOR) protein (Jobgen et al. 2006; Li et al. 2009; Bazer et al. 2012). Using trophectoderm cells derived from conceptuses on day 12 of gestation, we found that addition of 100 and 350 $\mu \mathrm{M}$ arginine to culture medium increased the abundance of total and phosphorylated proteins for MTOR, ribosomal protein S6 kinase 1, and eukaryotic initiation factor 4E-binding protein-1 


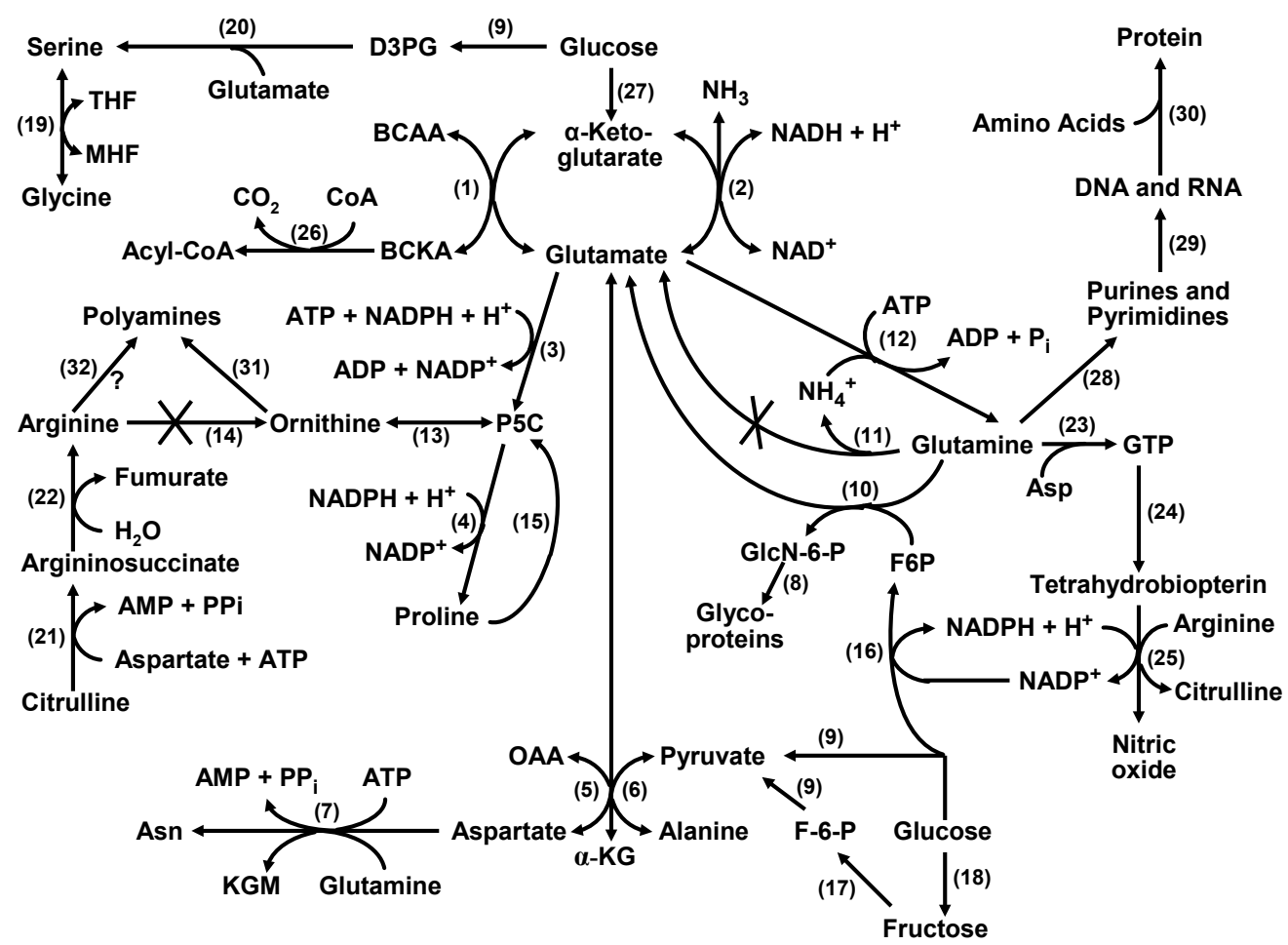

Fig. 3 Amino acid metabolism in the porcine placenta. The enzymes catalyzing the indicated reactions are: 1, BCAA transaminase; 2, glutamate dehydrogenase; 3, pyrroline-5-carboxylate synthase; 4, pyrroline-5-carboxylate reductase; 5, aspartate transaminase; 6 , alanine transaminase; 7 , asparagine synthetase; 8 , enzymes for synthesis of glycoproteins; 9 , enzymes of glycolysis; 10 , glutamine:fructose6-phosphate transaminase; 11, phosphate-dependent glutaminase; 12, glutamine synthetase; 13 , ornithine aminotransferase; 14 , arginase; 15 , proline oxidase; 16, enzymes of the pentose cycle; 17 , fructose kinase; 18. enzymes converting glucose into fructose; 19 , serine hydroxymethyl transferase; 20. enzymes for converting D-3-phosphoglycerate and glutamate into serine; 21, argininosuccinate synthase; 22, argininosuccinate lyase; 23, enzymes for GTP synthesis; 24, enzymes for converting GTP into tetrahydrobiopterin; $25, \mathrm{NO}$ synthase; 26 , branched-chain $\alpha$-ketoacid dehydrogenase; 27 , enzymes for converting glucose into $\alpha-K G ; 28$, enzymes for synthesis of nucleotides; 29 , enzymes for DNA and RNA synthesis; 30 , enzymes for protein synthesis; 31 , polyamine synthesis via ornithine decarboxylase, spermidine synthase, and spermine synthase; 32, putrescine synthesis via arginine decarboxylase and agmatinase. $\mathrm{BCAA}=$ branched-chain amino acids; $\mathrm{BCKA}=$ branched-chain $\alpha$-ketoacids; D3PG = D-3-phosphoglycerate; F6P = fructose-6-phosphate; GlcN-6-P = glucosamine-6-phosphate; HCys $=$ homocysteine; $\alpha-K G=\alpha$-ketoglutarate; $\mathrm{MTH}=N^{5}-N^{10}$-methylene tetrahydrofolate; $\mathrm{OH}$-Pro $=$ hydroxyproline; $\mathrm{KGM}=\alpha$-ketoglutaramate; $\mathrm{OAA}=$ oxaloacetate; $\mathrm{P} 5 \mathrm{C}=$ pyrroline-5-carboxylate; THF $=$ tetrahydrofolate. Adapted from Wu (2013). The porcine placenta contains no activity of phosphateactivated glutaminase (reaction 11) or arginase (reaction 14) (Self et al. 2004; Wu et al. 2005).

in a dose-dependent manner (Kong et al. 2012). Therefore, arginine at these concentrations stimulated protein synthesis and inhibited proteolysis, leading to enhanced proliferation of the cells (Kong et al. 2012). Inactivation of autophagy appears to be a major mechanism for AA to inhibit protein degradation in cells (Wu 2013). Interestingly, an inhibition of NO synthesis by $76 \%$ had only a modest effect on intracellular protein turnover in trophectoderm cells (e.g., a $13 \%$ decrease in protein synthesis and a 20\% increase in proteolysis) (Kong et al. 2012). Thus, 
arginine promotes growth of porcine placental cells largely via an NO-independent pathway. Results of recent studies indicate that glutamine and leucine also activate the MTOR pathway to stimulate protein synthesis in porcine and ovine trophectoderm cells (Kim et al. 2011a,b,c; 2012). Similar results have been reported for pregnant rats (Zheng et al. 2008; 2012).

\section{Mechanisms for amino acids to regulate fetal muscle growth and development}

Enhancing the availability of AA in the fetus can increase fetal growth through providing the building blocks and activating the MTOR signaling pathway to enhance muscle protein synthesis (Wu et al. 2010). Because myocytes and adipocytes are derived from a common mesenchymal precursor (Sordella et al. 2003), fetal skeletal muscle is formed maximally while differentiation of stem cells into preadipocytes is impaired in response to appropriate signals (e.g., transcription factors Myf5 and MyoD) that favor development of myocytes (Kablar et al. 2003). Thus, at birth, white adipose tissue in newborn pigs is only approximately $1 \%$, in striking contrast to 40\% muscle mass (Wu et al. 1999). There are two developing muscle fibers in fetal pigs: 1) primary fibers formed by the rapid fusion of primary myoblasts between $\mathrm{d} 25$ and 50 of gestation and 2) secondary fibers formed on the surface of primary fibers between approximately d 50 and 90 of gestation (Handel \& Stickland 1987; Bee 2004). The numbers of secondary muscle fibers, but not primary muscle fibers, are affected by the uterine environment (Dwyer et al. 1994) and the number of fetuses in utero (Town et al. 2004). Because the total number of muscle fibers is fixed at birth, their prenatal development impacts the postnatal growth of skeletal muscle (Nissen et al. 2003). The differences in prenatal and postnatal growth rates between IUGR piglets and normal litter mates correlate with a lower ratio of secondary to primary muscle fibers and a smaller size of the fibers in IUGR pigs (Handel \& Stickland 1987). Polyamines are necessary for both proliferation and differentiation of cells (Flynn et al. 2009) and likely mediate growth and development of fetal muscle fibers (Wu et al. 2010). In support of this view, concentrations of arginine, ornithine, proline, glutamine, and polyamines were reduced substantially in skeletal muscle of IUGR fetal pigs, compared with normal-body-weight (NBW) littermates (Wu et al. 2010). Similarly, concentrations of polyamines were much lower in allantoic and amniotic fluids of IUGR than in NBW fetal pigs (Wu et al. 2008). Whether dietary supplementation with polyamines can improve growth and development of fetal skeletal muscle has yet to be determined.

Intracellular protein turnover, adipogenesis, and mitochondrial biogenesis play major roles in regulating protein deposition in skeletal muscle and fat accretion in fetuses (Wu et al. 2010; Wang et al. 2012). In this regard, it is noteworthy that results of proteomics studies indicate that newborn IUGR piglets have a greater abundance of proteasomes (i.e., the major protease complex for nonlysosomal protein degradation) in skeletal muscle and liver, but less eukaryotic translation initiation factor 3, a key requirement for protein synthesis, in skeletal muscle, when compared with NBW piglets (Wang et al. 2008). Recently, Wang et al. (2013) reported that muscle fiber diameters were smaller in IUGR fetal pigs than in NBW fetal pigs on all days of gestation. Although the number of primary fibers did not differ between these two groups of fetal pigs on d 60 of gestation, the total number of muscle fibers in IUGR fetal pigs was lower on d 90 and 110 of gestation (amounting to a 25\% difference on d 110), when compared with NBW fetal pigs. Proteomic analysis revealed 37 differentially expressed proteins, which are involved in energy supply, protein metabolism, structure and type of muscle fibers, proliferation and differentiation of muscle fibers, nutrient transport, intracellular environment, and tissue integrity (Wang et al. 2013). Twenty five of these proteins were less abundant in IUGR fetal pigs, including transferrin, glutathione $S$-transferase omega-1, mitochondrial ATP synthase, 
myosin-7, citrate synthase, creatine kinase, and bifunctional purine biosynthesis protein. These findings provide some insight into mechanisms responsible for reduced growth and impaired development of skeletal muscle in IUGR piglets

\section{Use of functional AA to improve fetal survival and growth in pigs}

The current swine industry adopts restricted feeding programs to prevent excessive weight gain by gilts and sows during gestation (NRC 2012). Such a strategy can ameliorate farrowing difficulties and appetite reduction during lactation; however, gilts and sows do not receive sufficient amounts of dietary AA to support optimal embryonic and fetal growth during earlyto late-gestation (i.e., d 14 to 114) (Wu et al. 2010). This problem is exacerbated further by: 1) degradation of large amounts of dietary AA in the small intestine; and 2) the naturally occurring inability of placentae to supply an adequate amount of nutrients to fetuses in pigs. For example, due to extensive catabolism of arginine by arginase in the small intestine (Bergen $\&$ Wu 2009), $60 \%$ of dietary arginine enters the portal circulation of pregnant gilts (Wu et al. 2007a). Therefore, increasing dietary provision of arginine beyond that from a typical corn- and soybean meal-based diet may be an effective means to enhance circulating levels and improve fetal survival and growth in gestating swine. The following lines of experimental evidence support this hypothesis.

First, dietary supplementation with $1.0 \%$ arginine- $\mathrm{HCl}$ between $\mathrm{d} 30$ and 114 of gestation increased the number of live-born piglets by 2 and litter birth-weight by $24 \%$ (Mateo et al. 2007). The contents of crude protein and arginine in the basal diet were $12.2 \%$ and $0.70 \%$ (on an as-fed basis), respectively. The arginine to lysine ratio in the supplemental diet was 2.64, which did not affect intestinal absorption of lysine or histidine (Mateo et al. 2007). An arginine to lysine ratio of greater than 3:1 in the diet would likely result in antagonism among basic AA and should be avoided in dietary formulations (Wu et al. 2007b). Second, compared with control gilts, dietary supplementation with $0.4 \%$ or $0.8 \%$ L-arginine between d 14 and 25 of gestation increased placental growth by $21-34 \%$ and the number of viable fetuses per litter by approximately 2 (Li et al. 2011). Likewise, dietary supplementation with $1 \%$ arginine to gilts or sows between $d$ 14 and 28 of gestation increased the number of live-born piglets by approximately 1 at birth (Ramaekers et al., 2006). Third, supplementation with $1 \%$ arginine between $d 14$ and 28 of gestation increased the number of fetuses on $\mathrm{d} 70$ by 3 per litter and the ratio of secondary to primary muscle fibers in fetal pigs (Berard et al. 2009). Fourth, supplementing $1 \%$ arginine to gilts beginning on d 17 of gestation for 16 days increased placental weight by $16 \%$ and the number of live-born piglets per litter by 1.2 (Gao et al. 2012). Finally, dietary supplementation with $0.83 \%$ arginine between d 90 and 114 of gestation increased average birth weight of liveborn piglets by $16 \%$ (Wu X. et al. 2012). Collectively, well-designed studies have demonstrated beneficial effects of arginine supplementation on reproductive performance in gestating swine managed under practical production conditions.

As a functional AA, arginine acts in concert with other functional AA to further improve reproductive performance of pigs ( $\mathrm{Wu}$ et al. 2009). One of the functional AA is glutamine, whose uptake by the uterus of gestating gilts is the highest among all AA (Wu et al. 1999) and whose concentrations during late gestation are reduced (Wu et al. 2011). Supplementing a corn- and soybean meal-based diet (containing $0.70 \%$ arginine and $1.22 \%$ glutamine) with $0.4 \%$ arginine and $0.6 \%$ glutamine (on an as-fed basis) between d 30 and 114 of gestation prevented a decline in glutamine concentrations in the plasma of gilts (Wu et al. 2011) that occurred when only arginine was supplemented to the basal diet (Mateo et al. 2007). Supplemental arginine and glutamine markedly reduced: 1$)$ concentrations of ammonia $(-29 \%)$ and urea $(-27 \%)$ in maternal plasma (the reduction in both ammonia and urea indicate improved efficiency of 
utilization of dietary AA); 2) variation in birth weights among all piglets born (-27\%) and liveborn piglets $(-24 \%)$; and 3) the proportion of piglets with birth weights of 0.6 to $1.29 \mathrm{~kg}(-23 \%$ for all piglets born and $-22 \%$ for live-born piglets). Additionally, dietary supplementation with arginine plus glutamine increased: 1) the number of live-born piglets by 1.4 per litter; 2) litter birth weight for either all piglets born $(+10 \%)$ or live-born piglets $(+15 \%)$, and 3$)$ the proportion of piglets with birth weights of 1.3 to $1.49 \mathrm{~kg}(+37 \%$ for all piglets born and $+30 \%$ for live-born piglets). The proportion of piglets with heavier birth weights (1.5 to 1.69 or 1.7 to $2.09 \mathrm{~kg}$ ) did not differ between control and arginine plus glutamine-supplemented gilts (Wu et al. 2011). Collectively, our results indicate an important role for functional AA in improving pregnancy outcome in swine. These findings led to the recent recognition of arginine and glutamine as conditionally essential AA for growing and gestating pigs (NRC 2012).

\section{Concluding remarks}

Placental insufficiency contributes to high rates of embryonic/fetal mortality and the incidence of IUGR in swine. As building blocks of protein and regulators of metabolic pathways, inadequate or disproportionate amounts of AA in maternal diets are major factors affecting pregnancy outcomes. Many of the traditionally classified "nutritionally nonessential AA" are not adequate in conventional sow rations to meet demands of the fetus, because rates of their utilization are much greater than those for "nutritionally essential AA" that are not synthesized by animal tissues. Growing evidence shows that dietary supplementation with arginine to gilts or sows increases placental growth (including vascular growth), litter size, and litter birth weight. Also, a combination of arginine with glutamine during late gestation further improves fetal growth, while reducing variation in birth weights of piglets. These new results not only greatly advance basic knowledge about reproductive biology, but also have important implications for enhancing fetal survival and growth in swine and other livestock species (e.g., sheep and cattle).

\section{Declaration of interest}

The authors declare that there is no conflict of interest that could be perceived as prejudicing the impartiality of the review.

\section{Funding}

Work in our laboratories was supported by National Research Initiative Competitive Grants from the Animal Reproduction Program (2008-35203-19120) and Animal Growth \& Nutrient Utilization Program (2008-35206-18764) of the USDA National Institute of Food and Agriculture, Texas A\&M AgriLife Research (H-8200), the National Basic Research Program of China (2013CB127302), the National Natural Science Foundation of China (no. 31172217 and 31272450), China Postdoctoral Science Foundation (2012T50163), Chinese Universities Scientific Funds (No. 2012RC024), and the Thousand-People Talent program at China Agricultural University.

\section{References}

Ashworth CJ 1991 Effect of pre-mating nutritional status and post-mating progesterone supplementation on embryo survival and conceptus growth in gilts. Animal Reproductive Science 26 311-321.

Ashworth CJ, Finch AM, Page KR, Nwagwu MO \& McArdle HJ 2001 Causes and consequences of fetal growth retardation in pigs. Reproduction Supplement 58 233-46.

Bazer FW 1989 Allantoic fluid: regulation of volume and composition. In: Brace RA, Ross MG and Robillard JE (eds.), Reproductive and Perinatal Medicine Vol. 11: Fetal and Neonatal Body Fluids. Ithaca: Perinatology. 
pp. 135-155.

Bazer FW, Burghardt RC, Johnson GA, Spencer TE \& Wu G 2008 Interferons and progesterone for establishment and maintenance of pregnancy: Interactions among novel cell signaling pathways. Reproductive Biology 8 179-211.

Bazer FW, Kim JY, Song GH, Ka H, Wu G, Johnson GA \& Vallet JL 2013 Roles of selected nutrients on development of the conceptus during pregnancy. This book.

Bazer FW, Song GH, Kim JY, Erikson DW, Johnson GA, Burghardt RC, Gao HJ, Satterfield MC, Spencer TE \& Wu G 2012 Mechanistic mammalian target of rapamycin (MTOR) cell signaling: Effects of select nutrients and secreted phosphoprotein 1 on development of mammalian conceptuses. Molecular and Cellular Endocrinology 354 22-33.

Bazer FW, Spencer TE, Johnson GA, Burghardt RC \& Wu G 2009 Comparative aspects of implantation. Reproduction 138 195-209.

Bazer FW, Thatcher WW, Martinat-Botte F \& Terqui M 1988. Conceptus development in Large White and prolific Chinese Meishan pigs. Journal of Reproduction and Fertility 84 37-42.

Bee G 2004 Effect of early gestation feeding, birth weight, and gender of progeny on muscle fiber characteristics of pigs at slaughter. Journal of Animal Science $\mathbf{8 2}$ 826-836.

Bérard J \& Bee G 2010 Effects of dietary l-arginine supplementation to gilts during early gestation on foetal survival, growth and myofiber formation. Animal 4 1680-1687.

Bergen WG \& Wu G 2009 Intestinal nitrogen recycling and utilization in health and disease. Journal of Nutrition 139 821-825.

Dekaney CM, Wu G \& Jaeger LA 2003 Gene expression and activity of enzymes in the arginine biosynthetic pathway in porcine fetal small intestine. Pediatric Research 53 274-280.

Dwyer CM, Stickland NC \& Fletcher JM 1994 The influence of maternal nutrition on muscle fiber number development in the porcine fetus and on subsequent postnatal growth. Journal of Animal Science $\mathbf{7 2}$ 911-817.

Finch AM, Yang LG, Nwagwu MO, Page KR, McArdle HJ \& Ashworth CJ 2004 Placental transport of leucine in a porcine model of low birth weight. Reproduction 128 229-235.

Ford SP, Vonnahme KA \& Wilson ME 2002 Uterine capacity in the pig reflects a combination of uterine environment and conceptus genotype effects. Journal of Animal Science $\mathbf{8 0}$ E66-E73.

Gao KG, Jiang ZY, Lin YC, Zheng CT, Zhou GL, Chen F, Yang L \& Wu G 2012 Dietary L-arginine supplementation enhances placental growth and reproductive performance in sows. Amino Acids $\mathbf{4 2}$ 2207-2214.

Geisert RD \& Yelich JV 1997 Regulation of conceptus development and attachment in pigs. Journal of Reproduction and Fertility 52 (Suppl) 133-149.
Handel SE \& Stickland NC 1987 The growth and differentiation of porcine skeletal muscle fibre types and the influence of birthweight. Journal of Anatomy 152 107-119.

Jobgen WS, Fried SK, Fu WJ, Meininger CJ \& Wu G 2006. Regulatory role for the arginine-nitric oxide pathway in metabolism of energy substrates. Journal of Nutritional Biochemistry 17 571-588.

Kablar B, Krastel K, Tajbakhsh S \& Rudnicki MA 2003 Myf5 and MyoD activation define independent myogenic compartments during embryonic development. Developmental Biology 258 307-318.

Kim SW, Hurley WL, Wu G \& Ji F 2009 Ideal amino acid balance for sows during gestation and lactation. Journal of Animal Science 87 E123-132.

Kim JY, Burghardt RC, Wu G, Johnson GA, Spencer TE \& Bazer FW 2011a Select nutrients in the ovine uterine lumen: VII. Effects of arginine, leucine, glutamine, and glucose on trophectodem cell signaling, proliferation, and migration. Biology of Reproduction 84 62-69.

Kim JY, Burghardt RC, Wu G, Johnson GA, Spencer TE \& Bazer FW 2011b Select nutrients in the ovine uterine lumen: VIII. Arginine stimulates proliferation of ovine trophectoderm cells through mTOR-RPS6KRPS6 signaling cascade and synthesis of nitric oxide and polyamines. Biology of Reproduction 84 70-78.

Kim JY, Burghardt RC, Wu G, Johnson GA, Spencer TE \& Bazer FW 2011c Select nutrients in the ovine uterine lumen: IX. Differential effects of arginine, leucine, glutamine and glucose on interferon tau, ornithine decarboxylase and nitric oxide synthase in the ovine conceptus. Biology of Reproduction 84 1139-1147.

Kim JY, Song GW, Wu G \& Bazer FW 2012 Functional roles of fructose. Proceedings of National Academy of Science USA 109 E1619-1628.

Knight JW, Bazer FW, Thatcher WW, Frank DE \& Wallace HD 1977 Conceptus development in intact and unilaterally hysterectomized-ovariectomized gilts: interrelationships among hormonal status, placental development, fetal fluids, and fetal growth. Journal of Animal Science 44 620-637.

Kong XF, Tan BE, Yin YL, Gao HJ, Li XL, Jaeger LA, Bazer FW \& Wu G 2012 L-Arginine stimulates the mTOR signaling pathway and protein synthesis in porcine trophectoderm cells. Journal of Nutritional Biochemistry 23 1178-1183.

Li XL 2011 Regulation of porcine conceptus survival and growth by L-arginine. PhD Dissertation. Texas A\&M University, College Station, Texas.

Li XL, Bazer FW, Gao HJ, Jobgen WJ, Johnson GA, Li P, McKnight JR, Satterfield MC, Spencer TE \& Wu G 2009. Amino acids and gaseous signaling. Amino Acids 37 65-78.

Li XL, Bazer FW, Johnson GA, Burghardt RC, Erikson DW, Frank JW, Spencer TE, Shinzato I \& Wu G 2010 Dietary supplementation with $0.8 \%$ L-arginine between days 0 and 25 of gestation reduces litter size in gilts. Journal of Nutrition 140 1111-1116.

Mateo RD, Wu G, Bazer FW, Park JC, Shinzato I \& Kim SW 2007 Dietary L-arginine supplementation 
enhances the reproductive performance of gilts. Journal of Nutrition 137 652-656.

Meininger CJ \& Wu G 2002 Regulation of endothelial cell proliferation by nitric oxide. Methods in Enzymology 352 280-295.

National Research Council 2012 Nutrient Requirements of Swine. National Academy Press, Washington, D.C.

Nissen PM, Danielsen VO, Jorgensen PF \& Oksbjerg N 2003 Increased maternal nutrition of sows has no beneficial effects on muscle fiber number or postnatal growth and has no impact on the meat quality of the offspring. Journal of Animal Science 81 3018-3027.

Pond WG, Strachan DN, Sinha YN, Walker EF Jr, Dunn JA \& Barnes RH 1969 Effect of protein deprivation of swine during all or part of gestation on birth weight, postnatal growth rate and nucleic acid content of brain and muscle of progeny. Journal of Nutrition 99 61-67.

Pond WG, Yen JT, Mauer RR \& Christenson RK 1981 Effect of doubling daily energy intake during the last two weeks of pregnancy on pig birth weight, survival and weaning weight. Journal of Animal Science $\mathbf{5 2}$ 535-541.

Ramaekers P, Kemp B \& van der Lende T 2006 Progenos in sows increases number of piglets born. Journal of Animal Science 84 (Suppl 1) 394 (Abstract).

Reynolds LP, Caton JS, Redmer DA, Grazul-Bilska AT, Vonnahme KA, Borowicz PB, Luther JS, Wallace JM, Wu G \& Spencer TE 2006 Evidence for altered placental blood flow and vascularity in compromised pregnancies. Journal of Physiology 572 51-58.

Schmidt W 1992 The amniotic fluid compartment: the fetal habitat. Advances in Anatomy, Embryology and Cell Biology 127 1-98.

Self JT, Spencer TE, Johnson GA, Hu J, Bazer FW \& Wu G 2004 Glutamine synthesis in the developing porcine placenta. Biology of Reproduction 70 1444-1451.

Smith SB, Mersmann HJ, Smith EO, Britain KG 1999 Stearoyl-coenzyme A desaturase gene expression during growth in adipose tissue from obese and crossbred pigs. Journal of Animal Science 77 17101716.

Sordella R, Jiang W, Chen GC, Curto M \& Settleman L 2003 Modulation of Rho GTPase signaling regulates a switch between adipogenesis and myogenesis. Cell 113 147-158.

Tilley RE, McNeil CJ, Ashworth CJ, Page KR, McArdle HJ 2007 Altered muscle development and expression of the insulin-like growth factor system in growth retarded fetal pigs. Domestic Animal Endocrinology 32 167-77.

Town SC, Putman CT, Turchinsky NJ, Dixon WT \& Foxcroft GR 2004 Number of conceptuses in utero affects porcine fetal muscle development. Reproduction 128:443-454.

Town SC, Patterson JL, Pereira CZ, Gourley G \& Foxcroft GR 2005 Embryonic and fetal development in a commercial dam-line genotype. Animal Reproductive Science 85 301-316.

Trahair JF \& Harding R 1995 Restitution of swallowing in the fetal sheep restores intestinal growth after midgestation esophageal obstruction. Journal of
Pediatric and Gastroenteral Nutrition 20 156-161.

Vallet JL, Leymaster KA \& Christenson RK 2002 The influence of uterine function on embryonic and fetal survival. Journal of Animal Science $\mathbf{8 0}$ (E. Suppl 2) E115-E125.

Vallet JL \& Freking BA 2006 Changes in fetal organ weights during gestation after selection for ovulation rate and uterine capacity in swine. Journal of Animal Science 84 2338-45.

Vallet JL, Miles JR, Freking BA 2009 Development of the pig placenta. Society of Reproduction and Fertility Supplement 66 265-79.

Vonnahme K \& Ford SP 2004 Placental vascular endothelial growth factor receptor system mRNA expression in pigs selected for placental efficiency. Journal of Physiology 554 194-201.

Vonnahme K, Wilson ME, Foxcroft GR \& Ford SP 2002 Impacts on conceptus survival in a commercial swine herd. Journal of Animal Science 80 553-559.

Wang JJ, Chen LX, Li DF, Yin YL, Wang XQ, Li P, Dangott LJ, Hu WX \& Wu G 2008 Intrauterine growth restriction affects the proteomes of the small intestine, liver and skeletal muscle in newborn pigs. Journal of Nutrition 138 60-66.

Wang JJ, Wu ZL, Li DF, Li N, Dindot SV, Satterfield MC, Bazer FW \& Wu G 2012 Nutrition, epigenetics, and metabolic syndrome. Antioxidants and Redox Signaling 17 282-301.

Wang WW, Wu ZL, Dai ZL, Yang Y, Wang JJ \& Wu G 2013 Glycine metabolism in animals and humans: implications for nutrition and health. Amino Acids. doi: 10.1007/s00726-013-1493-1.

Wu G 2009 Amino acids: metabolism, functions, and nutrition. Amino Acids 37 1-17.

Wu G 2013. Amino Acids: Biochemistry and Nutrition, CRC Press, Boca Raton, USA.

Wu G 2010a. Recent advances in swine amino acid nutrition. Journal of Animal Science and Biotechnology 1 49-61.

Wu G 2010b. Functional amino acids in growth, reproduction and health. Advances in Nutrition 1 31-37.

Wu G, Bazer FW, Cudd TA, Jobgen WS, Kim SW, Lassala A, Li P, Matis JH, Meininger CJ \& Spencer TE 2007a Pharmacokinetics and safety of arginine supplementation in animals. Journal of Nutrition 137 1673S-1680S.

Wu G, Bazer FW, Cudd TA, Meininger CJ \& Spencer TE 2004 Maternal nutrition and fetal development. Journal of Nutrition 134 2169-2172.

Wu G, Bazer FW, Datta S, Johnson GA, Li P, Satterfield MC \& Spencer TE 2008 Proline metabolism in the conceptus: Implications for fetal growth and development. Amino Acids 35 691-702.

Wu G, Bazer FW, Davis TA, Jaeger LA, Johnson GA, Kim SW, Knabe DA, Meininger CJ, Spencer TE, Yin YL 2007b Important roles for the arginine family of amino acids in swine nutrition and production. Livestock Science 112 8-22.

Wu G, Bazer FW, Davis TA, Kim SW, Li P, Rhoads JM, 
Satterfield MC, Smith SB, Spencer TE \& Yin YL 2009 Arginine metabolism and nutrition in growth, health and disease. Amino Acids 37 153-168.

Wu G, Bazer FW, Hu J, Johnson GA \& Spencer TE 2005 Polyamine synthesis from proline in the developing porcine placenta. Biology of Reproduction 72 842-850.

Wu G, Bazer FW \& Tuo W 1995 Developmental changes of free amino acid concentrations in fetal fluids of pigs. Journal of Nutrition 125 2859-2868.

Wu G, Bazer FW, Tuo T \& Flynn SP 1996 Unusual abundance of arginine and ornithine in porcine allantoic fluid. Biology of Reproduction 54 12611265.

Wu G, Bazer FW, Wallace JM \& Spencer TE 2006 Intrauterine growth retardation: Implications for the animal sciences. Journal of Animal Science $\mathbf{8 4}$ 2316-2337.

Wu G, Bazer FW, Burghardt RC, Johnson GA, Kim SW, Li XL, Satterfield MC \& Spencer TE 2010 Impacts of amino acid nutrition on pregnancy outcome in pigs: mechanisms and implications for swine production. Journal of Animal Science 88 E195-E204.

Wu G, Bazer FW, Johnson GA, Knabe DA, Burghardt RC, Spencer TE, Li XL, Wang JJ 2011 Important roles for L-glutamine in swine nutrition and production. Journal of Animal Science 89 2017-2030.

Wu G, Wu ZL, Dai ZL, Yang Y, Wang WW, Liu C, Wang B, Wang JJ \& Yin YL 2013 Dietary requirements of "nutritionally nonessential amino acids" by animals and humans. Amino Acids 441107-1113.
Wu G \& Meininger CJ 2002 Regulation of nitric oxide synthesis by dietary factors. Annual Review of Nutrition 22 61-86.

Wu G, Ott TL, Knabe DA \& Bazer FW 1999 Amino acid composition of the fetal pig. Journal of Nutrition 129 1031-1038.

Wu G, Pond WG, Flynn SP, Ott TL \& Bazer FW 1998a Maternal dietary protein deficiency decreases nitric oxide synthase and ornithine decarboxylase activities in placenta and endometrium of pigs during early gestation. Journal of Nutrition 128 2395-2402.

Wu G, Pond WG, Ott TL \& Bazer FW 1998b Maternal dietary protein deficiency decreases amino acid concentrations in fetal plasma and allantoic fluid of pigs. Journal of Nutrition 128 894-902.

Wu X, Yin YL, Liu YQ, Liu XD, Liu ZQ, Li TJ, Huang RL, Ruan Z, Deng ZY 2012 Effect of dietary arginine and $\mathrm{N}$-carbamoylglutamate supplementation on reproduction and gene expression of eNOS, VEGFA and PIGF1 in placenta in late pregnancy of sows. Animal Reproduction Science 132 187-192.

Zeng XF, Wang FL, Fan X, Yang WJ, Zhou B, Li PF, Yin YL, Wu G \& Wang JJ 2008 Dietary arginine supplementation during early pregnancy enhances embryonic survival in rats. Journal of Nutrition 138 1421-1425.

Zeng XF, Mao XB, Huang ZM, Zhang FR, Zhang SH, Ren M, Wu GY \& Qiao SY 2010 Arginine enhances embryo implantation in rats through $\mathrm{PI} 3 \mathrm{~K} / \mathrm{Akt} / \mathrm{mTOR} /$ NO signaling pathway during early pregnancy. PLoS One 7(7) e41192. 